International Journal of Advanced Trends in Computer Science and Engineering

Available Online at http://www.warse.org/IJATCSE/static/pdf/file/ijatcse0291.32020.pdf

https://doi.org/10.30534/ijatcse/2020/0291.32020

\title{
Front-End Development of Nutrient Film Technique for Hydroponic Plant with IoT Monitoring System
}

\author{
Raja Siti Nur Adiimahbinti Raja Aris, Khairul IrwanFikri bin Mohammad, Lia SafiyahbintiSyafie, \\ Farah Hanan bintiAzimi, Suzanna bintiRidzuan Aw \\ University College TATI, Malaysia, nuradiimah@tatiuc.edu.my
}

\begin{abstract}
Soil salinity is one of the most devastating environmental stresses which causes major reductions in cultivated land area, crop productivity and quality. The salinity issue has led to grow plants in solution as an alternative method, such as Nutrient Film Technique (NFT). This paper is focusing on front end development of hydroponic system where users are able to monitor and control two important parameters in plant growth which are $\mathrm{EC}$ and $\mathrm{pH}$ parameters. This process is executed systematically through the use of internet of thing (IoT) technology. This project development is designed to provide automatics control of two main parameters for leafy greens growth. The parameters are monitored using Liquid Crystal Display (LCD) and IoT platform. Using ESP32 microcontroller board, this project manages to maintain an optimum condition for nutrient consumed by the plant. EC and $\mathrm{pH}$ value can be controlled using smartphones via Blynk application, which provides real time changes. This offers advantage for the user to monitor and control the system with less effort and requires no presence at the farmed area. The developed system is proven to provide a sufficient nutrient for plant growth with hassle free built in automatic control and monitoring system.
\end{abstract}

Key words: Hydroponic System, Internet of Thing (IoT), Nutrient Film Technique (NFT), Vertical Farming.

\section{INTRODUCTION}

In these recent years, global scarcity of water resources, environmental pollution and increased salinization of soil and water have become a serious environmental issue which led to global impact to agricultural ecosystem. Among these issue, Shahbaz and Ashraf (2013) mentioned that soil salinity is one of the most devastating environmental stresses which causes major reductions in cultivated land area, crop productivity and quality [1]. According to Pitman and Läuchli (2002) at least $20 \%$ of all irrigated land is soil affected, with some estimated being as high as $50 \%$. It has been estimated that more than $50 \%$ of the arable land would be salinized by the year 2050 [2].
In parallel with world's growing population, food supply becomes one of the most challenging demands to be fulfilled. From this significant decrease in agricultural land caused by the mentioned salinity issue, growing plants in solution culture become more popular. Compared to traditional growing method, hydroponics provides plants with extra oxygen in the growth phase which stimulates root growth. Faster nutrient absorption for plants with sufficient oxygen in the root area is helpful to fasten the plant growth.

While this farming method has been around since Middle Ages, many developments have been made it far more efficient and affordable. With no soil required, hydroponic becomes more effective using thin film of nutrient flows through plastic channel called Nutrient Film Technique (NFT). Developed by Dr Allan Cooper in 1960's this technique contains the plant roots with no solid planting media. The root will develop partly in the shallow stream of recirculating solution and partly above the solution. NFT requires special attention to several parameters such as the water temperature, water level, acidity $(\mathrm{pH})$, and the concentration of the nutrient (EC/PPM).

Conventionally, NFT is controlled manually with human intervention which requires time and human resources. Thus, this paper is focusing on front end development of hydroponic system where users are able to monitor and control the parameters systematically with internet of thing technology where the hardware system can be controlled via finger touch. This offers special advantage for the user or farmer to monitor and control the system with less effort and requires no presence at the farmed area. This developed NFT techniques with monitoring system provides parameter control using a user friendly interface.

\section{LITERATURE SURVEY}

This section deliberates the research and finding that have been made by previous researcher as an account of what has been published related to this project. It is a focused review on technology development used in the project.

Mahaidayu et al., (2017) has presented a paper on plant cultivation using Nutrient Film Technique (NFT) hydroponic system. It is stated that plants in this system need nutrient 
solution to grow well. TDS, $\mathrm{pH}$ and temperature of the nutrient solution must be checked to ensure plant gets sufficient nutrients. This particular previous work had developed monitoring system of NFT hydroponic where farmers are able to monitor $\mathrm{pH}$, TDS and temperature online. Farmer can easily decide which plant is suitable to be cultivated and time to boost growth [3].

The work presented by Zhao et al., (2010) on the study on control networks and information networks integration of IoT technology based on the actual situation of agricultural production. Remote monitoring system with internet and wireless communications is combined to design an information management system for agricultural monitoring research facilities. In this research, it shows that the greenhouse monitoring system based on loT technology has certain precision of monitor and control. According to the surrounding monitoring requirement, the system has realized the automatic control on both the environmental temperature and humidity factors. The system has offered a good growth condition, it is easy to operate, the interface is friendly, and offering the real time environmental factors in the greenhouse [4].

The ideas from Palande et al., (2018) are challenge of plant growing in remote areas such as deserts and north and south pole due to an unpredictable weather. The paper presented a system that can grow common plant and vegetables without depending on the weather by introducing the hydroponic system. The system is automated controlled by using the microcontroller and sensor with minimum guided. In order to improved reliablity and control automated, the system was applied with Internet of Thing (IoT) network. The Titan Smartponics project is developed with automated control and human interface are unnecessarily once the germinated plant done into the system [5].

Siregar et al., (2018) proposed a monitoring system embedded with PH sensor, Electro Conductivity Sensor,water temperature sensor, air temperature, Light Sensor, GSM / GPRS, Open Garden Shield, Open Garden Hydroponic, and Arduino Uno as main board or microcontroller. The result shows that the number of leaves and plant height for lettuce and red spinach is changed after two week testing indicated that the sensor and system working properly. The Arduino is used as a microcontroller to monitor the changes of $\mathrm{pH}$, nutrition, water temperature, air temperature and light intensity in the hydroponic plantation [6].

Patil et al., (2016) undertook research to develop automation in hydroponic system. Hydroponic concept is the method of growing plants in water without using soil. The nutrient and fertilizers are supplied directly through the water. In order to control the plants growth, an Automated Monitoring and controlling environment like temperature, humidify, light intensity etc is proposed. All the parameter will response to the respective sensors. If these values exceed or decrease their corresponding set points, the system starts the controlling action and set back to its normal value [7].

Eridani et al., (2018) conducted a research on a prototype scaled Nutrient Film Technique (NFT) hydroponics for nutrition feeding by using an automation system. The system is designed with a control center using the Arduino UNO R3 board. The GP2Y0A21 proximity sensor is used as water level detector, while the TDS sensor as a detector of electrical conductivity of the nutrient solution. The system equipped with the servo motor as an opening device of the faucet in the nutrient container. The result shown that the system proposed is successfully to control water delivery automatically when the water level is less than the minimum level and be able to add the nutrients automatically when the nutrient solution concentration is below 800ppm [8].

Adhau et al., (2018), introduced a self-controlled automated hydroponics system where the data in real time is use to control the counteractive steps. The aims of this project is to construct a smart and intelligent system with an optimization used of present technology.

The real time data will be imported from a low cost AVR microcontroller board. The NI LabVIEW will monitor all the data and send this data over the network for IoT application. The traditional PID controller is implementing for tuning control. The system has been tested and verified successfully [9].

Sisyanto et al., (2018) proposed the collaboration system between Cyber Physical Social System (CPSS), and hydroponic farmers. The new ideas is development of hydroponic smart farming system that can be monitored online via Telegram Messenger. The significant parameter in the hydroponics system, such as light intensity, room temperature, humidity, $\mathrm{pH}$, nutrient temperature, and Electrical Conductivity (EC) can be monitored based on that design. The prototype is build using Raspberry Pi 3 that connects directly with sensors such as DHT11 module, LDR, $\mathrm{pH}$ sensor module, and EC sensor. Telegram BOT is designed to allow the sensor be monitored online via Telegram. With the integration of the Physical System (Raspberry Pi, sensor) and Social System (Telegram Messenger) connected online via internet or cyber, the hydroponic system monitoring becomes more flexible [10-11].

\section{FRONT END DEVELOPMENT}

NFT technique used in this project is applied to recirculate the nutrient flow in order to supply all required nutrients for plant growth. This system uses rich oxygen nutrient solution flow through grow tray, back to reservoir and will be recirculated. This project is focused in automatically control system used to continuously regulate two important elements in the nutrient solution of a hydroponic system. Those two elements are; $\mathrm{pH}$ value and the nutrient concentration which is tested in form of 
electrical conductivity. The values are continuously being sensed by respective sensor to maintain the nutrient solution in the right condition for lettuce growth. Using Espressif ESP32 as the microcontroller, the data from both sensors is transferred into web hosting and database server. User is able to monitor the plant growth and control the parameters online with permissible buffer changing time.

The general front end development of this project is proposed as shown in Figure 1. The design of the hydroponic garden is developed in vertical cultivation made of plastic piping due several considerations. Taking mobility as the first consideration, this design offers great result in mobility. Using plastic piping as the main housing, it carries a lightweight and this design also can be considered as relatively small in size comparing other material such as wood and metal, this material is known to be cheaper, durable and lightweight. Space cautious is also one of the consideration which decides the design to be in vertical. Higher number of plants can be cultivated with same area by using this design compared to traditional horizontal cultivation. With many growing spaces for the plant cultivation and small space required to place of the hydroponic garden, this project can be installed easily and anywhere.

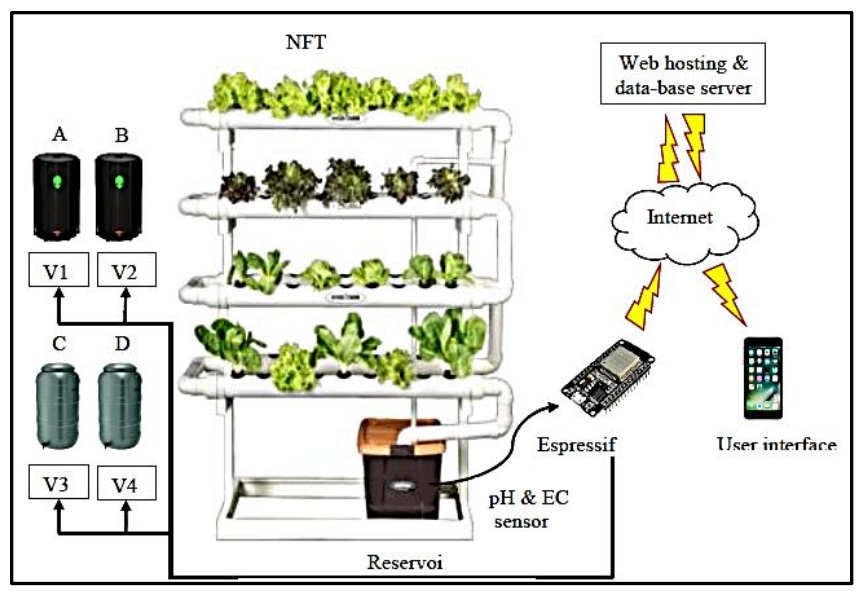

Figure 1: System Setup

Optimum pipe diameter is considered in this design for leafy plant growth. So, in this project round pipes are used for fast-growing leafy green and small lettuce growth. The shape and dimension of pipes used in this research is as shown in Figure 2.

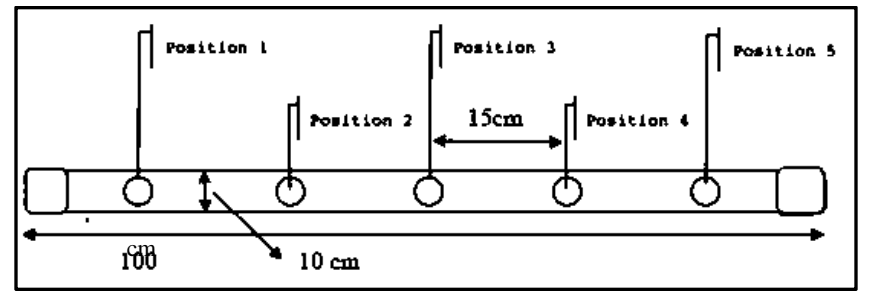

Figure 2: Grow Pipe Dimension
PVC piping with diameter of $10 \mathrm{~cm}$ is chose as the main frame for the growing pipe. Seven and a half in diameter of pipe is considered wide but vital to avoids plant selection limitations because the small plants can always be grown in the larger pipes, although there would be a sacrifice in planting density. Plants with extensive root systems, including mature older plants, can clog smaller pipes and cause overflows and losses of water.

It is recommended to build shorter length of growing pipe as nutrient deficiencies can occur in longer growing pipe, especially in plants towards the end of the pipes because the first plants have already stripped the nutrients. A slope of of pipe length is also equipped to make sure the water flows through the whole pipe with ease.

The hydroponic system for this research is developed as shown in Figure 3. The system consists of several vital elements that are required to provide conducive surrounding effect on the plant cultivation. The reservoir tank is used to store nutrient solution which will be dispensed and regulated throughout the system. Besides that, there is also four tanks of solution that being kept elevated above the reservoir by using simple PVC pipe structure. The position of the tank is rational for providing the best gravitational pull to dispense all the solution when needed. As mentioned, the grow tray is also designed and installed to be as levelling slope with approximately one inch drop for the whole tray length. It is important as the slope provide enough flow rates for the nutrient regulation inside the system.

Table 1: Part Label

\begin{tabular}{|c|c|}
\hline Symbol & Explanation \\
\hline A & Nutrient mixture tank \\
\hline B & Reserve water tank \\
\hline C & $\mathrm{pH}$ down solution tank \\
\hline D & $\mathrm{pH}$ up solution tank \\
\hline V1, V2, & Electric solenoid valves \\
V3 \& V4 & \\
\hline
\end{tabular}

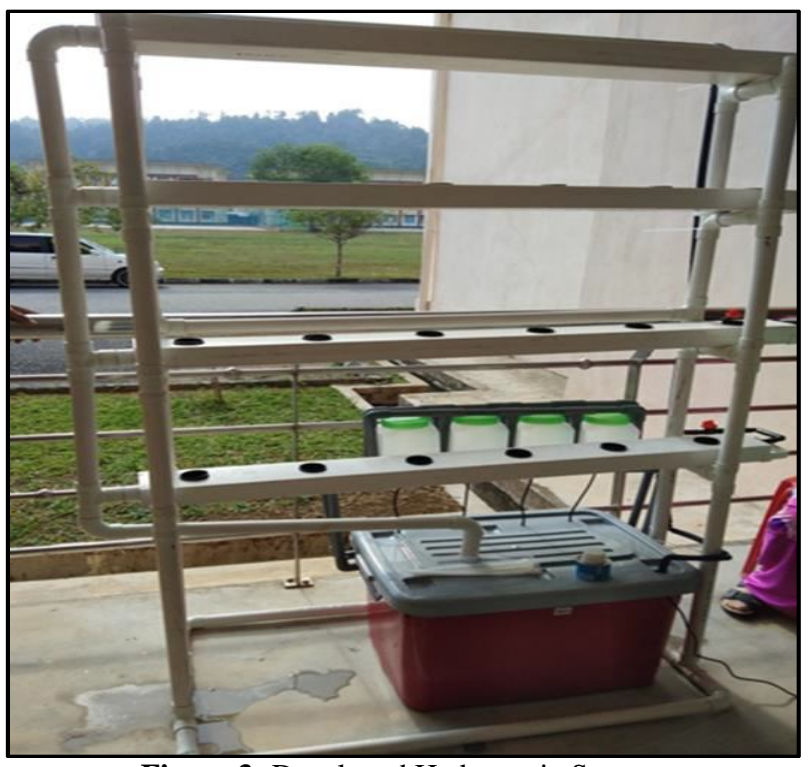

Figure 3: Developed Hydroponic System 
The piping system for the nutrient flow is also designed to be separated for each tray level, equipped with a water valve for each level. That way, the pressure can be control before it enters every level and the best pressure providing sufficient nutrient flow rates before it reaches the plants. The whole system design is created to achieve three main things, which are durable, lightweight and space-saving. Vertical hydroponic design using PVC piping structure had managed to utilized the proposed objectives and could afford to cultivates a total of 24 plants in a time, six plants per row in total of four levels.

Two main sensors detecting the primary parameters, conductivity(EC) and $\mathrm{pH}$ sensors and also another digital temperature sensor are submerged in the reservoir tank. The flow rate sensor is also installed through the first poly piping which provides the pumped nutrient solution to the system. These sensors are expected to provide live mainstream of data through the ESP32 microcontroller, directly to the server by $\mathrm{Wi}-\mathrm{Fi}$ internet protocol. Once the microcontroller is connected to the internet provider, it will simultaneously send all data and provides automatic regulation of the nutrient's EC and $\mathrm{pH}$ parameter. Domain of the data server is using BLYNK online server, once pair up with a smartphone, all data required would be displayed on the phone screen. a control box is customized to connect all sensors and actuator needed to run the complete system, which the ESP32 microcontroller plays the most important role in collecting all data from sensors, projecting it online and use the data to successfully regulate the nutrients solution parameters. The system's control box is equipped with a (16x4) LCD screen on top of the box. The LCD is also set to display real-time sensors measurement from the system where users could always refer to. The control box is shown in Figure 4 below.

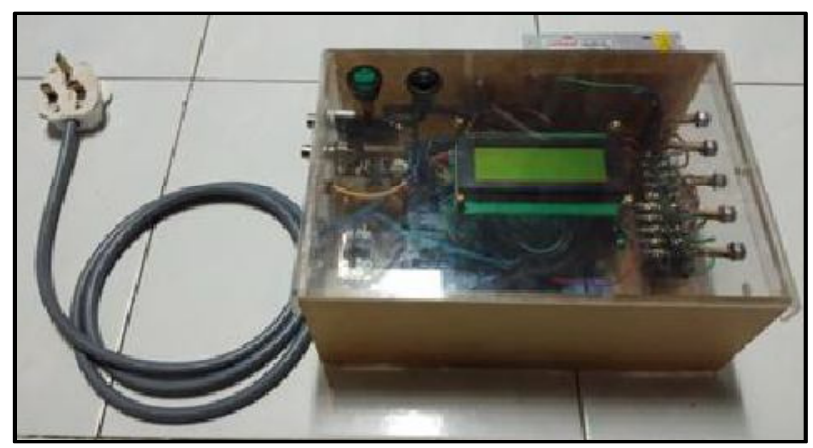

(a)

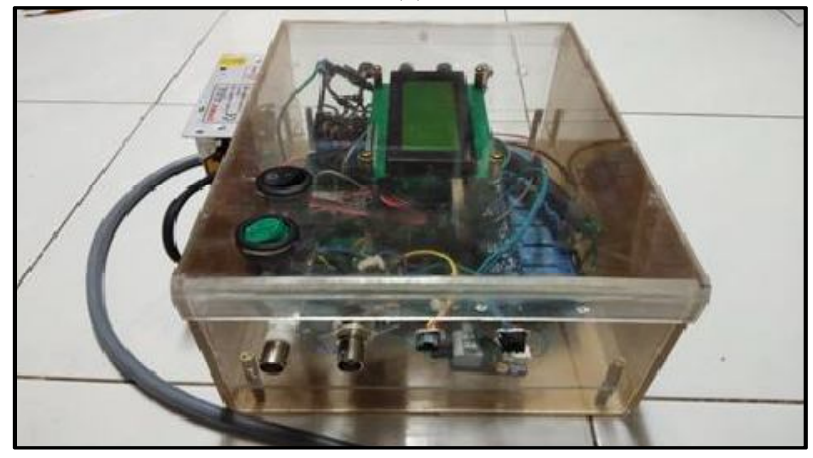

(b)

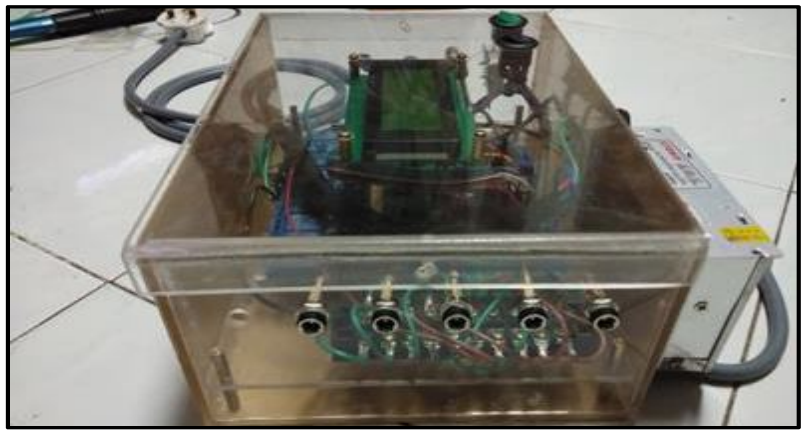

(c)

Figure 4: Control box of the NFT monitoring system $\begin{array}{lll}\text { (a) Front view } & \text { (b) Left view (c) Right view }\end{array}$

The sensors ports are prepared in line as shown in Figure 4(b). Starting from the $\mathrm{pH}$ sensor from the left, EC sensor is next, follow with flow rate sensor port and the temperature sensor port as the last one. There are four mini valves used in this system each are purposely to execute different output to regulate different changes in parameter.Two valves are subjected to increase the EC regulation value until it reaches the range of EC parameter. The third and fourth valves are consecutively subjected to increase and decrease the changes in $\mathrm{pH}$ regulation value until it enters the range of $\mathrm{pH}$ parameter. All connection to the valves is gathered on the right side of the control box to make a space for the valves port.

\section{RESULTS AND DISCUSSION}

The developed system will monitor and control the required parameter by using the Blynk application. This is shown in Figure 5. With the implementation of this IoT application, all the data from sensors can be obtained continuously. Reference values of EC and $\mathrm{pH}$ are initially set.

All parameters value from BLYNK application are measured and converted into line charts as in Figure 6 (a) to (d). The charts are simplified with average values for each parameter proportional to the time range. User can monitor the details information of $\mathrm{EC}$ value, $\mathrm{pH}$, temperature and flow rate. The value for $\mathrm{EC}$ and $\mathrm{pH}$ can be initially set up in the Blynk application. From the data collected, the average EC value taken is within the optimum value which is less than 1.5 $\mathrm{mS} / \mathrm{cm}$. For $\mathrm{pH}$ values, the measured data is in between 5 to 7 optimum value. The temperature data is only for monitoring purpose. The optimum temperature value is between $25-28^{\circ} \mathrm{C}$ to ensure the plant grow well. Referring to the Figure 6 (c), the temperature value is at minimum $27^{\circ} \mathrm{C}$ and at maximum value $29^{\circ} \mathrm{C}$. The maximum temperature value reached at $29^{\circ} \mathrm{C}$ during time duration 12 to $1 \mathrm{pm}$. Average flow rate value of 4.09 to $4.12 \mathrm{l} / \mathrm{min}$ is proven to be an optimum flow rate value for the root to absorb the nutrient effectively using this system. The system will compare the actual value with reference value and perform corrective action accordingly. 


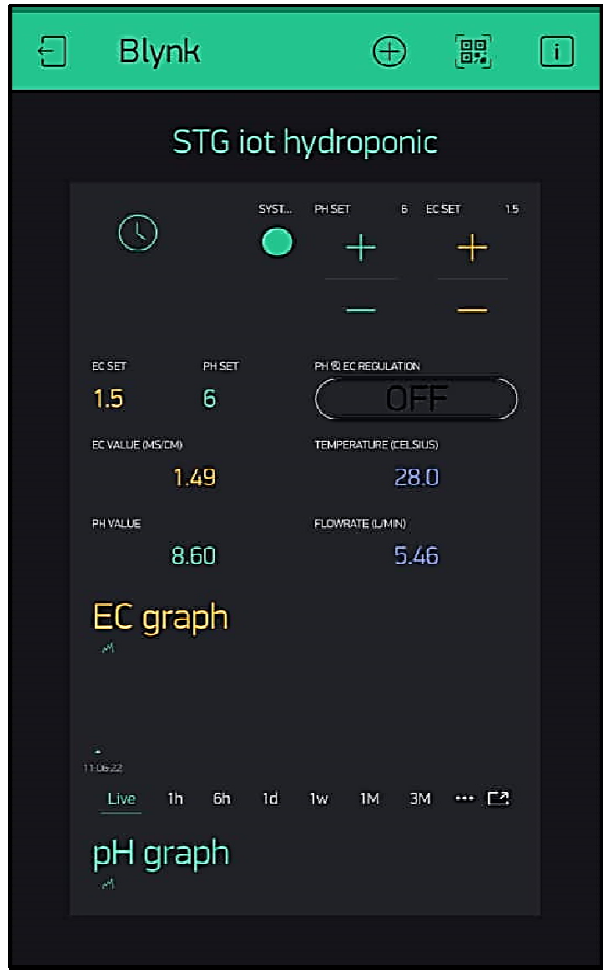

Figure 5: BLYNK Application Interface

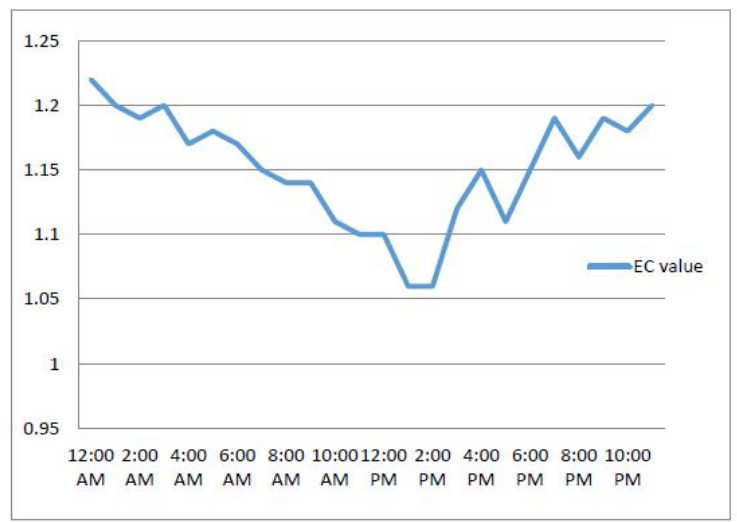

(a)

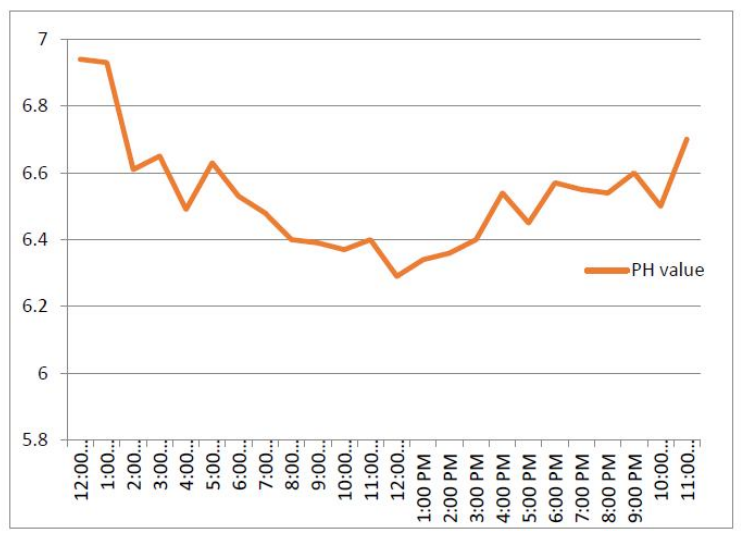

(b)

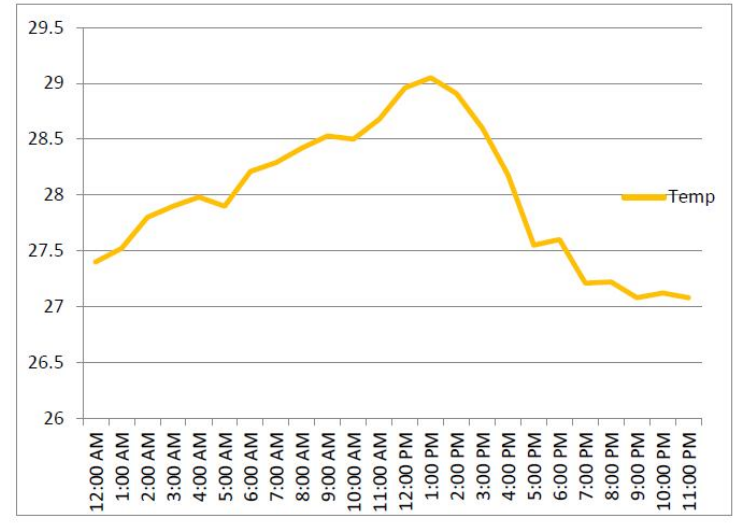

(c)

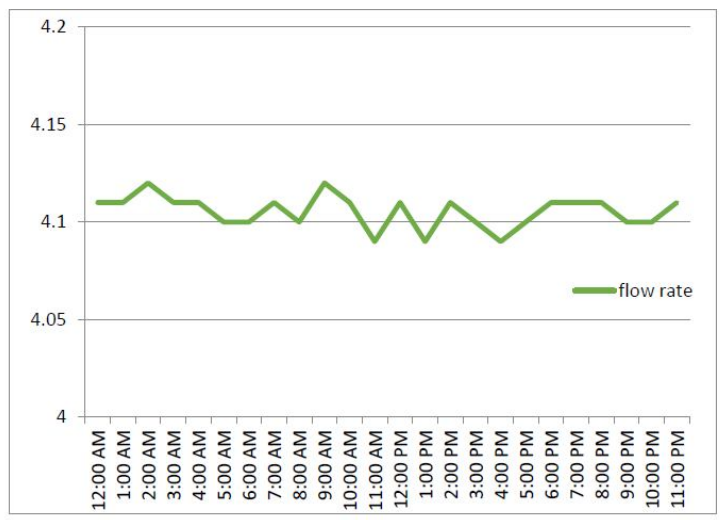

(d)

Figure 6: Parameters value

(a) EC value (b) $\mathrm{pH}$ value (c) Temperature value

(d) Flow rate value

\section{CONCLUSION}

The limitations of conventional technique for hydroponic system has led to a successful development of NFT for hydroponic plant that can be controlled and monitored automatically. The characteristics in the developed Blynk application for the system includes monitoring the details information of flow rate, temperature, $\mathrm{EC}, \mathrm{pH}$ value and temperature. The user able to control the system either through desktop or smartphones method where the hardware system can be controlled via finger touch. This method will give another benefit to user without the need to be at the farmed area.

\section{ACKNOWLEDGEMENT}

This research is fully supported by Short Term Grant, 9001.

\section{REFERENCES}

1. M. Shahbaz and M. Ashraf, "Improving Salinity Tolerance in Cereals," Critical Reviews in Plant Sciences. 2013. https://doi.org/10.1080/07352689.2013.758544 
2. M. G. Pitman and A. Läuchli, "Chapter 1 Global Impact Of Salinity And Agricultural Ecosystems Agricultural losses caused by salinity are difficult to assess but estimated to be substantial and expected to increase with time . Secondary salinization of agricultural lands is particular," pp. 3-20, 2002. https://doi.org/10.1007/0-306-48155-3_1

3. M. G. Mahaidayu, H. Helmy, A. Nursyahid, T. A. Setyawan, and A. Hasan, "Nutrient Film Technique ( NFT ) Hydroponic Monitoring System," J. Appl. Inf. Commun. Technol., vol. 1, no. 1, pp. 1-6, 2017.

4. J. C. Zhao, J. F. Zhang, Y. Feng, and J. X. Guo, "The study and application of the IOT technology in agriculture," in Proceedings - 2010 3rd IEEE International Conference on Computer Science and Information Technology, ICCSIT 2010, 2010.

5. V. Palande, A. Zaheer, and K. George, "Fully Automated Hydroponic System for Indoor Plant Growth," Procedia Comput. Sci., vol. 129, pp. 482-488, 2018. https://doi.org/10.1016/j.procs.2018.03.028

6. B. Siregar, S. Efendi, H. Pranoto, R. Ginting, U. Andayani, and F. Fahmi, "Remote monitoring system for hydroponic planting media," 2017 Int. Conf. ICT Smart Soc. ICISS 2017, vol. 2018-January, pp. 1-6, 2018. https://doi.org/10.1109/ICTSS.2017.8288884

7. P. Patil, S. Kakade, S. Kantale, and D. Shinde, "Automation in Hydroponic System Using PLC," Int. J. Scirntific Tech. Adv., vol. 2, no. 2, pp. 69-71, 2016.

8. D. Eridani, O. Wardhani, and E. D. Widianto, "Designing and implementing the arduino-based nutrition feeding automation system of a prototype scaled nutrient film technique (NFT) hydroponics using total dissolved solids (TDS) sensor," Proc. - 2017 4th Int. Conf. Inf. Technol. Comput. Electr. Eng. ICITACEE 2017, vol. 2018-January, pp. 170-175, 2018. https://doi.org/10.1109/ICITACEE.2017.8257697

9. S. Adhau, R. Surwase, and K. H. Kowdiki, "Design of fully automated low cost hydroponic system using LabVIEW and AVR microcontroller," Proc. 2017 IEEE Int. Conf. Intell. Tech. Control. Optim. Signal Process. INCOS 2017, vol. 2018-February, pp. 1-4, 2018. https://doi.org/10.1109/ITCOSP.2017.8303091

10. R. E. N. Sisyanto, Suhardi, and N. B. Kurniawan, "Hydroponic smart farming using cyber physical social system with telegram messenger," 2017 Int. Conf. Inf. Technol. Syst. Innov. ICITSI 2017 - Proc., vol. 2018-January, pp. 239-245, 2018. https://doi.org/10.1109/ICITSI.2017.8267950

11. Pooja Mittal , Navita. A Survey on Internet of Things (IoT) Based Healthcare Monitoring System. International Journal of Advanced Trends in Computer Science and Engineering. Volume 8, No.4, July - August 2019 https://doi.org/10.30534/ijatcse/2019/90842019 